\title{
Tracking forest phenology and seasonal physiology using digital repeat photography: a critical assessment
}

\section{Citation}

Keenan, T. F., B. Darby, E. Felts, O. Sonnentag, M. A. Friedl, K. Hufkens, J. O'Keefe, et al. 2014. "Tracking Forest Phenology and Seasonal Physiology Using Digital Repeat

Photography: a Critical Assessment." Ecological Applications 24 (6) (September): 1478-1489. doi:10.1890/13-0652.1.

\section{Published Version}

doi:10.1890/13-0652.1

\section{Permanent link}

http://nrs.harvard.edu/urn-3:HUL.InstRepos:13578514

\section{Terms of Use}

This article was downloaded from Harvard University's DASH repository, and is made available under the terms and conditions applicable to Other Posted Material, as set forth at http:// nrs.harvard.edu/urn-3:HUL.InstRepos:dash.current.terms-of-use\#LAA

\section{Share Your Story}

The Harvard community has made this article openly available.

Please share how this access benefits you. Submit a story.

Accessibility 


\title{
Tracking forest phenology and seasonal physiology using digital repeat photography: a critical assessment
}

\author{
T. F. Keenan, ${ }^{1,2,9}$ B. Darby,${ }^{3}$ E. Felts, ${ }^{4}$ O. Sonnentag,,${ }^{1,5}$ M. A. Friedl, ${ }^{6}$ K. Hufkens, ${ }^{6,7}$ J. O'Keefee, ${ }^{8}$ \\ S. Klosterman, ${ }^{1}$ J. W. Munger,${ }^{4}$ M. Toomey, ${ }^{1}$ and A. D. Richardson ${ }^{1}$ \\ ${ }^{1}$ Department of Organismic and Evolutionary Biology, Harvard University, Cambridge, Massachusetts 02138 USA \\ ${ }^{2}$ Department of Biological Sciences, Macquarie University, North Ryde, New South Wales 2109 Australia \\ ${ }^{3}$ Department of Biology, Boston University, Boston, Massachusetts 02215 USA \\ ${ }^{4}$ School of Engineering and Applied Sciences and Department of Earth and Planetary Sciences, Harvard University, \\ Cambridge, Massachusetts 02138 USA \\ ${ }^{5}$ Département de géographie, Université de Montréal, Montréal, Quebec H3T 1J4 Canada \\ ${ }^{6}$ Department of Earth and Environment, Boston University, Boston, Massachusetts 02215 USA \\ ${ }^{7}$ Isotope Bioscience Laboratory, Faculty of Bioscience Engineering, Ghent University, Ghent, East Flanders 9000 Belgium \\ ${ }^{8}$ Harvard Forest, Harvard University, 324 North Main Street, Petersham, Massachusetts 01366 USA
}

Abstract. Digital repeat photography is becoming widely used for near-surface remote sensing of vegetation. Canopy greenness, which has been used extensively for phenological applications, can be readily quantified from camera images. Important questions remain, however, as to whether the observed changes in canopy greenness are directly related to changes in leaf-level traits, changes in canopy structure, or some combination thereof.

We investigated relationships between canopy greenness and various metrics of canopy structure and function, using five years (2008-2012) of automated digital imagery, ground observations of phenological transitions, leaf area index (LAI) measurements, and eddy covariance estimates of gross ecosystem photosynthesis from the Harvard Forest, a temperate deciduous forest in the northeastern United States. Additionally, we sampled canopy sunlit leaves on a weekly basis throughout the growing season of 2011. We measured physiological and morphological traits including leaf size, mass (wet/dry), nitrogen content, chlorophyll fluorescence, and spectral reflectance and characterized individual leaf color with flatbed scanner imagery.

Our results show that observed spring and autumn phenological transition dates are well captured by information extracted from digital repeat photography. However, spring development of both LAI and the measured physiological and morphological traits are shown to lag behind spring increases in canopy greenness, which rises very quickly to its maximum value before leaves are even half their final size. Based on the hypothesis that changes in canopy greenness represent the aggregate effect of changes in both leaf-level properties (specifically, leaf color) and changes in canopy structure (specifically, LAI), we developed a two end-member mixing model. With just a single free parameter, the model was able to reproduce the observed seasonal trajectory of canopy greenness. This analysis shows that canopy greenness is relatively insensitive to changes in LAI at high LAI levels, which we further demonstrate by assessing the impact of an ice storm on both LAI and canopy greenness.

Our study provides new insights into the mechanisms driving seasonal changes in canopy greenness retrieved from digital camera imagery. The nonlinear relationship between canopy greenness and canopy LAI has important implications both for phenological research applications and for assessing responses of vegetation to disturbances.

Key words: carbon cycling; deciduous forest phenology; digital repeat photography; green chromatic coordinate; green-down; ice storm; MODIS; near-surface remote sensing; PhenoCam.

\section{INTRODUCTION}

Photosynthesis by terrestrial vegetation represents the primary means by which carbon dioxide $\left(\mathrm{CO}_{2}\right)$ is removed from the atmosphere. Vegetation structure

Manuscript received 8 April 2013; revised 27 August 2013; accepted 3 December 2013; final version received 3 February 2014. Corresponding Editor: W. J. D. van Leeuwen.

${ }^{9}$ E-mail: trevor.keenan@mq.edu.au and function typically varies seasonally, controlled in part by the onset and rate of leaf growth and senescence (Lieth 1974). Such phenological cycles respond directly to climate, serving as indicators of the potential impacts of climate change (IPCC 2007), and generate feedbacks to the climate system (Peñuelas et al. 2009, Richardson et al. 2013a). It is therefore important to develop systems capable of monitoring phenology and the physiological state and function of terrestrial vegetation. 
Phenology has been an area of active interest for centuries. Observer-based records primarily focused on the timing of bud burst and flowering, and are now used to quantify long-term responses of these events to climate change (Aono and Kazui 2008, Thompson and Clark 2008). In recent decades, ground-based techniques (e.g., Smolander and Stenberg 1996, Barr et al. 2004) have been developed that allow seasonal changes in canopy leaf area to be tracked using site-specific observations made at discrete time intervals. The development of satellite remote sensing not only allows phenological dates to be estimated on a global scale (e.g., Zhang et al. 2006), but also supports studies examining large-scale temporal changes in vegetation indices (e.g., $\mathrm{Xu}$ et al. 2013). Such global land-surface phenology approaches, however, are limited by the coarse temporal and spatial scale of remote sensing data sets and by the lack of adequate ground validation data (White et al. 2009, Hufkens et al. 2012a).

Automated near-surface remote sensing techniques have recently been developed as a bridge between ground-based manual observations and satellite remote sensing products (Richardson et al. 2013b). To accomplish this, imaging sensors or radiometric instruments are mounted above the canopy to record optical properties of canopy reflectance at a high temporal resolution. Off-the-shelf digital cameras are increasingly being used in this manner as an inexpensive, automated means by which to quantify temporal changes in canopy optical properties (e.g., Sonnentag et al. 2012). In particular, separate extraction of brightness levels for red, green, and blue (RGB) color channels from camera images allows indices to be calculated that describe changes in canopy greenness over time.

The expanding digital image archive (e.g., the PhenoCam network [available online] $)^{10}$ has been widely used to study temporal changes in vegetation canopies. Phenophase transition dates of leaf emergence and senescence derived from repeat digital imagery have been shown to parallel the phenology signal inferred from above- and below-canopy radiometric instruments (Richardson et al. 2007). Technical issues of camera choice and calibration have been examined, along with issues of scene illumination (Sonnentag et al. 2012). Phenological transition dates derived from camera imagery have been used to explain temporal changes in surface-atmosphere $\mathrm{CO}_{2}$ exchange (Ahrends et al. 2008, 2009, Richardson et al. 2009), improve the parameterization of phenology models (Migliavacca et al. 2012), and have been compared with satellite-based land surface phenology products (Hufkens et al. 2012a). Encouraged by their demonstrated effectiveness for canopy monitoring, automated digital cameras have become an integral part of continental-scale monitoring networks (e.g., the Integrated Carbon Observation

${ }^{10}$ http://phenocam.sr.unh.edu/
System and the National Ecological Observatory Network).

Although seasonal cycles in canopy coloration are evident from digital repeat photography (Sonnentag et al. 2012), open questions remain as to how the information extracted from digital images corresponds to the seasonal development of canopy structure and function. Changes in foliage related to phenology and ontogeny (i.e., developmental stage or age) occur in various aspects of leaf physiology (e.g., leaf color and pigmentation, leaf mass per unit area, water and nutrient content, photosynthetic capacity, etc.) over the course of the growing season (Ma et al. 2011, McKown et al. 2013). Although canopy greenness is commonly assumed to be a surrogate for canopy structure and function, the validity of such assumptions remains untested. For example, in time series of deciduous forest canopy greenness, a pronounced spike often marks the end of the rapid phase of spring greenup, preceding a gradual decline in greenness over the course of the summer. Although related to phenology, the mechanisms (physiological, morphological, or structural) directly responsible for the seasonal dynamics in canopy greenness have yet to be identified.

We explore relationships among seasonal changes in canopy greenness, which we measured using digital repeat photography, seasonal changes in canopy structure, and the physiological and morphological traits of individual leaves. Specifically, we assess the relationship between camera-derived canopy greenness and measurements of both canopy- and leaf-level traits for five years (2008-2012) at Harvard Forest, a temperate deciduous forest in the northeastern United States. We first assess seasonal cycles and interannual variability of cameraderived greenness (and the related phenological transitions) using ground observations of phenology, leaf area index, and eddy covariance $\mathrm{CO}_{2}$ flux measurements. We then use physiological and morphological measurements on individual leaves to understand the mechanisms driving the seasonality of canopy greenness. Our goal is to identify when and under what circumstances information derived from digital repeat photography can be used to draw inferences about seasonal changes in leaf- and canopy-level traits related to structure and function.

\section{Materials And Methods}

\section{Study site}

The study was conducted at the Harvard Forest Environmental Measurement Site (EMS; $42.5378^{\circ} \mathrm{N}$, $72.1715^{\circ} \mathrm{W}$ ), located in central Massachusetts, USA. The site is a temperate forest dominated by hardwoods including red oak (Quercus rubra, 36\% basal area) and red maple (Acer rubrum, 22\% basal area), with other hardwoods, such as yellow birch (Betula alleghaniensis), also present. The site has annual mean precipitation of $110 \mathrm{~cm}$, distributed fairly evenly throughout the year, and a mean annual temperature of $7.1^{\circ} \mathrm{C}$. 


\section{Digital camera settings, image acquisition, and analysis}

Canopy images were collected using an automated and networked digital camera (StarDot Netcam SC 1.3 MP [StarDot, Buena Park, California, USA]) mounted on top of a tower $30 \mathrm{~m}$ above the surface, with an oblique viewing angle $\left(20^{\circ}\right.$ from horizontal) across the canopy. Minimally compressed JPEG images from the digital camera were taken at regular intervals (every 30 min between 04:00 and 21:30 local time), transferred via file transfer protocol (FTP) and stored on the server of the PhenoCam network (see footnote 10). Automatic white balancing was turned off on the camera unit to minimize day-to-day variability (Richardson et al. 2007, 2009). Aperture size was fixed but the exposure time was adjusted in response to changing light levels. Canopy greenness was quantified using the green chromatic coordinate $\left(G_{\mathrm{cc}}\right)$, which uses red $(R)$, green $(G)$, and blue $(B)$ digital numbers to calculate the ratio of green within the image $\left(G_{\mathrm{cc}}=G /(R+G+B)\right)$. $G_{\mathrm{cc}}$ was calculated using the PhenoCam Image Processor V1.0 (available online). ${ }^{11}$ This software tool allows a region of interest within the camera field of view to be specified and calculates $G_{\mathrm{cc}}$ based on the method described by Sonnentag et al. (2012). Phenophase transition dates for spring bud burst, maximum greenness, and leaf senescence were estimated using two different approaches: a curve-fitting method (Elmore et al. 2012) and a simple threshold-crossing approach. For the threshold-crossing approach, spring and fall transition dates were identified as the point at which the three-day running mean crossed a threshold value. We used $33 \%$ of the annual amplitude as the threshold for both spring and autumn transition points. For the curve-fitting approach (Elmore et al. 2012), transition dates were extracted from curve fits by numerically calculating the dates of extrema in the curvature change rate, following the approach used in the moderate resolution imaging spectroradiometer (MODIS) phenology product (Zhang et al. 2003). Uncertainty in the extracted transition dates was estimated using 1000 Monte Carlo samples based on the covariance matrix of parameter estimates. Five years (2008-2012) of continuous camera imagery were used.

\section{Canopy structure}

Leaf area index (LAI) measurements (Li-Cor LAI2000 [Li-Cor, Lincoln, Nebraska, USA]) were made weekly during the growing season for 5 years (20082012) at 40 plots established in 1993 using a stratified random position along eight 500-m transects, running SW and NW from the EMS tower along the dominant wind directions (Barford et al. 2001).

Ground observations of spring and autumn phenology (budbreak, leaf development, leaf coloration, and

\footnotetext{
${ }^{11} \mathrm{http}: / /$ phenocam.sr.unh.edu/webcam/tools/
}

leaf fall) for the dominant tree species (red oak, $n=4$ individuals) were made from 2008 to 2012 at 3-7 d intervals (Richardson and O'Keefe 2009). These observations were used to identify the dates of bud burst, proportional leaf size, and leaf senescence at 50\%, 75\%, and $95 \%$ of maximum.

Top-of-canopy broadband normalized difference vegetation index (NDVI) estimates were made based on measurements of reflected radiation at 400-700 and 305-2800 nm following Jenkins et al. (2007). Specifically, upwelling and downwelling PAR (photosynthetically active radiation) and solar radiation were measured at 30-min intervals using upward and downward pointing Kipp and Zonen CMP 3 thermopile pyranometers (Kipp and Zonen, Delft, The Netherlands) and LICOR (LI190SB-L) quantum radiation sensors (Li-Cor, Lincoln, Nebraska, USA) on a walk-up tower located adjacent to the EMS tower.

To estimate LAI from the radiation measurements, gap fraction $(P)$ was first calculated as $P=\mathrm{Qt} / \mathrm{Qo}$, where Qo is incident solar photosynthetic photon flux density (PPFD) measured above the canopy and Qt is the PPFD measured below the canopy. Measurements of $P$ were used when the solar zenith angle was closest to $57^{\circ}$, and LAI was calculated for each sample $(\mathrm{LAI}=-\log (P) / K$, where $K=G(57) / \cos (57))$. Measurements at $57^{\circ}$ were used because at this point all leaf inclination distribution functions $(G)$ converge to 0.5 . Daily LAI was then estimated by averaging the two LAI values per day in order to consider foliar clumping effects (Ryu et al. $2010 b$ ) and then smoothed with a spline function.

Satellite-based daily canopy reflectance for the period 2000-2011 was measured using the MODIS on the Terra satellite (MOD09GA). Reflectance data were screened for clouds (including cirrus and cloud shadows), high-viewing zenith angle $\left(>60^{\circ}\right)$, and low retrieval quality using standard MODIS quality assurance data layers (Vermote et al. 2011). The screened daily reflectance data was then used to calculate the normalized difference vegetation index and the enhanced vegetation index (NDVI, EVI; Huete et al. 2002).

Leaf inclination angles of red oak were estimated at monthly intervals in 2011 using the leveled digital camera approach proposed and evaluated by Ryu et al. (2010c) and Pisek et al. (2011), respectively. In brief, leveled digital images were taken with a Pentax K100D digital single-lens reflex camera (Pentax, Tokyo, Japan) along vertical tree profiles at 2-m intervals (Pisek et al. 2013). Leaf inclination angles were estimated using the public domain image processing software ImageJ (available online) $^{12}$ as outlined in Pisek et al. (2013).

Gross-canopy daily ecosystem photosynthesis (GEP) was estimated for 4 y (2008-2011) using eddy covariance measurements of net ecosystem $\mathrm{CO}_{2}$ exchange (Urbanski et al. 2007, Keenan et al. 2012). GEP was calculated

12 http://rsbweb.nih.gov/ij/ 
on an hourly basis as the difference between ecosystem respiration and net ecosystem carbon uptake, and integrated to daily sums.

\section{Leaf physiological and morphological traits}

Leaf samples were collected from upper-level canopy leaves of three dominant red oak (Quercus rubra) trees surrounding a walk-up tower adjacent to the EMS instrument tower for the entire 2011 growing season. Each sample consisted of five, nondamaged, sunlit leaves collected from one branch of each tree. Samples were collected every 3-4 d for the first month following bud burst, then once per week until leaf abscission in midNovember. All measurements were made directly after sampling, following a period of dark adaptation (30 min; Richardson and Berlyn 2002).

Spectral measurements of leaf reflectance and transmittance were made using an ASD FieldSpec 3 portable spectrometer (Analytical Spectral Devices, Boulder, Colorado, USA). The spectrometer was connected to a 5-cm, three-port integrating sphere and a $10-\mathrm{W}$ hemispheric collimated light source. The sphere had an $8^{\circ}$ near-normal incidence port, meaning that reflectance measurements included spectral and diffuse components. The manufacturer's RS3 software (Analytical Spectral Devices, Boulder, Colorado, USA) was used to control the spectrometer. The spectral range measured was 350-2500 nm at 1-nm increments. Each recorded spectral measurement consisted of 50 individual scans. A white Spectralon (Opti-Sciences, Hudson, New Hampshire, USA) reference standard was taken for calibration for each leaf measured. Raw spectral data was processed using ViewSpecPro (Analytical Spectral Devices, Boulder, Colorado, USA). Spectral measurements were made from day-of-year 157. Spectral indices (ChlNDI (chlorophyll normalized difference index), [(R750 - R705)]/[(R750 + R705)], [Gitelson et al. 2006, 2009]; PRI (photochemical reflectance index $),[(\mathrm{R} 531-\mathrm{R} 570)] /[(\mathrm{R} 531+\mathrm{R} 570)]$, [Gamon et al. 1992, 1997]; NDVI, [(R750 - R675)]/ [(R750 + R675)], [Gamon et al. 1997, Gamon and Surfus 1999]; MTCI (MERIS terrestrial chlorophyll index $),[(\mathrm{R} 753.75-\mathrm{R} 708.75)] /[(\mathrm{R} 708.75+\mathrm{R} 681.25)]$, [Dash and Curran, 2004]) were calculated from the leaf level reflectance for each measurement. In these calculations, R750, for example, is the red digital number measured at $750 \mathrm{~nm}$.

Chlorophyll fluorescence measurements were made using a hand-held Opti-sciences OS-30p fluorometer (Opti-Sciences, Hudson, New Hampshire, USA). Five readings were taken randomly across each dark-adapted leaf to calculate the average measurement for the leaf. Measurements were given as the ratio of variable fluorescence to maximum fluorescence $\left(F_{\mathrm{v}} / F_{\mathrm{m}}\right)$.

To measure broadband reflectance in the red, green, and blue wavelengths, each leaf was scanned using an Epson 3170 flatbed scanner (Epson, Suwa, Nagano, Japan). A paint sample strip, consisting of varying shades of green progressing from light to dark, was included in each scan as a reference standard. The scanned images were analyzed to extract leaf area and leaf color (red, green, and blue digital numbers).

Leaf fresh mass was measured the day of collection, after which leaves were placed in manila coin envelopes in an oven at $60^{\circ} \mathrm{C}$ for $3-5 \mathrm{~d}$ to dry before measuring their dry mass. Leaf fresh and dry mass, in combination with leaf size, were used to calculate leaf mass per unit area (LMA) and leaf water content.

At the end of the growing season, the leaf samples were grouped by week for carbon and nitrogen analysis. The dried leaves were ground using a mortar and pestle, pouring a small amount of liquid nitrogen over the sample. The mortar and pestle was cleaned using ethanol between samples to prevent cross-sample contamination. A 3-5 $\mu$ g sample from the ground leaves was then microbalanced. The sample was then put in a capsule in preparation for nitrogen and carbon analysis. Carbon $(\mathrm{C})$ and nitrogen $(\mathrm{N})$ content were measured by flash combustion/oxidation using a Thermo Finnigan Flash EA 1112 elemental analyzer (Thermo Fisher Scientific, Waltham, Massachusetts, USA; $0.06 \%$ C and $0.01 \% \mathrm{~N}$ detection limits); we express $\mathrm{C}$ and $\mathrm{N}$ data in terms of concentration $(\mathrm{g} / 100 \mathrm{~g}$ dry matter, expressed as a percentage) and content per unit leaf area $\left(\mathrm{g} \mathrm{N} / \mathrm{cm}^{2}\right)$.

\section{Linear mixing model}

Linear mixing models are useful tools for summarizing changes in observations caused by differences in the proportional contribution of so-called end-members (Adams et al. 1995). For this analysis, we used a mixing model with two end-members to test the hypothesis that seasonal changes in camera-derived greenness could be explained by a combination of canopy LAI (controlling the relative contribution of leaf vs. background) and seasonal changes in leaf color. Because the contribution of both these end-members is proportional to the leaf area within the camera field of view, both were modified by a scaling factor dependent on LAI. More formally, our model is expressed as

$$
G_{\mathrm{cc}}(t)=\left(1-F_{t}\right) G_{\mathrm{cc}}^{\mathrm{B}}+F_{t} G_{\mathrm{cc}}^{\mathrm{L}}(t)
$$

where $G_{\mathrm{cc}}(t)$ is the camera-derived green chromatic coordinate at time $t, G_{\mathrm{cc}}^{\mathrm{B}}$ is the mean background (winter) camera-derived green chromatic coordinate, $G_{\mathrm{cc}}^{\mathrm{L}}(t)$ is the scanner-derived green chromatic coordinate of individual leaves, and $F_{t}$ is the fraction of the camera field of view that contains green leaves. Following Beer's law, $F_{t}$ is a nonlinear function of LAI and can be estimated as $F_{t}=1-\exp (-k \operatorname{LAI}(t))$, where $k$ is an optimized parameter to account for clumping and the oblique viewing angle of the camera. Therefore, $k$ is the only free parameter in the model and is optimized by minimizing the root mean-square error between the model predictions and the observed camera $G_{\mathrm{cc}}$ values. 


\section{Results}

Phenology of greenness, leaf area index, and gross primary productivity

The characteristic seasonal cycle of camera-derived $G_{\text {cc }}$ (e.g., Sonnentag et al. 2012) was observed each year (Fig. 1). Typical characteristics of this cycle include a steep rise and clear peak in spring, followed by a continuous decline over summer and a steep decline during autumn to a constant minimum in winter. Spring LAI followed the steep rise in spring $G_{\mathrm{cc}}$, although LAI consistently lagged $G_{\mathrm{cc}}$ (Fig. 1). In contrast to the spring peak and subsequent summer decline of $G_{\mathrm{cc}}$, LAI continued to increase after peak $G_{\mathrm{cc}}$ and did not decline until autumn. On average, declines in autumn LAI lagged declines in autumn $G_{\mathrm{cc}}$, reflecting changing leaf color before actual leaf abscission.

An ice storm in December 2008 significantly damaged the canopy at Harvard Forest and led to a $22 \%$ reduction in midsummer LAI in 2009 compared to 2008 (Fig. 1). Midsummer $G_{\mathrm{cc}}$ was relatively unaffected by this large decline in LAI, suggesting that $G_{\mathrm{cc}}$ is insensitive to changes in leaf area at high LAI levels. Mean midsummer LAI increased steadily each year from 2009 through 2012 and had almost recovered to pre-ice-storm levels within four years.

Daily GEP was highly correlated with both LAI $\left(R^{2}=\right.$ $0.79, p<0.01)$ and $G_{\mathrm{cc}}\left(R^{2}=0.76, P<0.01\right)$. As with LAI, increases in spring GEP lagged increases in $G_{\mathrm{cc}}$. The timing and rate of increase in spring GEP matched the rate of increase in spring LAI in all years except 2008 (Fig. 1). A late-summer decline in GEP was evident in most years, which did not closely match either $G_{\mathrm{cc}}$ or LAI. In contrast to previous suggestions that hue is more correlated to GEP and LAI than $G_{\mathrm{cc}}$ (Mizunuma et al. 2013), we found no positive correlation between hue and GEP $(R=-0.2, P=0.03)$ or LAI $(R=-0.3, P<$ $0.01)$ at our site. Indeed the seasonal cycle of hue is critically dependent on the color balance of the camera (Appendix: Fig. A1) and is thus unlikely to be suitable for multisite applications.

\section{Phenological transitions}

Spring bud burst and autumn coloration dates obtained from the camera images were positively correlated with the ground observation. Spring bud burst dates from ground observations varied by two weeks over the five years (2008-2012), with the earliest bud burst on day 116 and the latest on day 128. Bud burst dates extracted using a green-down sigmoid model (Elmore et al. 2012) correlated well $\left(R^{2}=0.66\right.$, $P<0.1)$ with interannual variability in observed bud burst dates, with a mean bias of $3.5 \mathrm{~d}$ (Fig. 2a). However, dates extracted from the sigmoid model exhibited lower variance than the field observations. The Elmore model performed poorly at predicting late springs (Fig. 2a), giving a slope between observed and predicted that differed significantly from 1.0. A spring bud burst $G_{\mathrm{cc}}$ threshold of 0.38 (15\% of the mean amplitude; Fig. 2a) identified dates that were more highly correlated to the field observations $\left(R^{2}=0.95, P\right.$ $<0.01)$ than those from the green-down model, suggesting that the sigmoid model approach could potentially be improved. Peak $G_{\mathrm{cc}}$, estimated by curve fitting, corresponded to the previously mentioned spike in greenness that immediately follows the rapid spring green-up. The timing of peak $G_{\mathrm{cc}}$ corresponded most closely to $50 \%$ leaf size, with leaves not reaching their maximum size until 2-3 weeks later (Fig. 2b). Autumn dates of maximum coloration were particularly well captured by the green-down sigmoid model $\left(R^{2}=0.84\right.$, $P<0.1$; Fig. 2c).

\section{Phenology of leaf-level traits}

The measured physiological and morphological leaf traits showed marked seasonal dynamics. In particular, chlorophyll fluorescence $\mathrm{F}_{\mathrm{v}} / \mathrm{F}_{\mathrm{m}}$, area and mass, and nitrogen, carbon, and water content, took roughly $35 \mathrm{~d}$ from bud burst to reach their maximum values (Fig. 3). This phenology of leaf-level traits was not captured by broadband NDVI, camera $G_{\mathrm{cc}}$, or the MODIS EVI and NDVI products (Fig. 3). Each of these metrics reached their maximum about two weeks after bud burst, which is about two weeks before the end of spring leaf elongation. Chlorophyll indices (MTCI, ChlNDI) calculated from leaf-level spectral reflectance indicate that leaf chlorophyll content increased throughout most of the summer, with declines becoming apparent around day 240. In contrast, PRI from the leaf-level spectra was relatively constant throughout the season, declining only at the start of leaf coloration in the autumn (Fig. 3). Leaf angle, previously hypothesized to be a potential cause of changes in canopy greenness (Sonnentag et al. 2012), was relatively constant throughout the year in our data. It should be noted that leaf angle measurements directly after bud burst were not made.

\section{Linking phenology of leaf color, canopy structure, and camera $G_{\mathrm{cc}}$}

Sampled leaves were scanned on a flatbed scanner and leaf color information (red, green, and blue digital numbers) was extracted from the resulting images. Early season leaves were bright yellowish-green, leading to high values of scanner derived $G_{\mathrm{cc}}$ (Fig. 4). Green and red declined sharply throughout spring (and to a lesser extent through summer) until autumn, when red increased as leaves changed color before senescing. The blue component of leaves gradually increased throughout the season. The net effect was a steady decline in leaf level $G_{\mathrm{cc}}$ throughout summer, with a sharp decline in autumn (Fig. 4), which paralleled patterns observed in the camera-derived $G_{\mathrm{cc}}$.

To test whether seasonal changes in camera $G_{\mathrm{cc}}$ could be explained by a combination of observed dormant season canopy color, leaf area index, and leaf color, we 


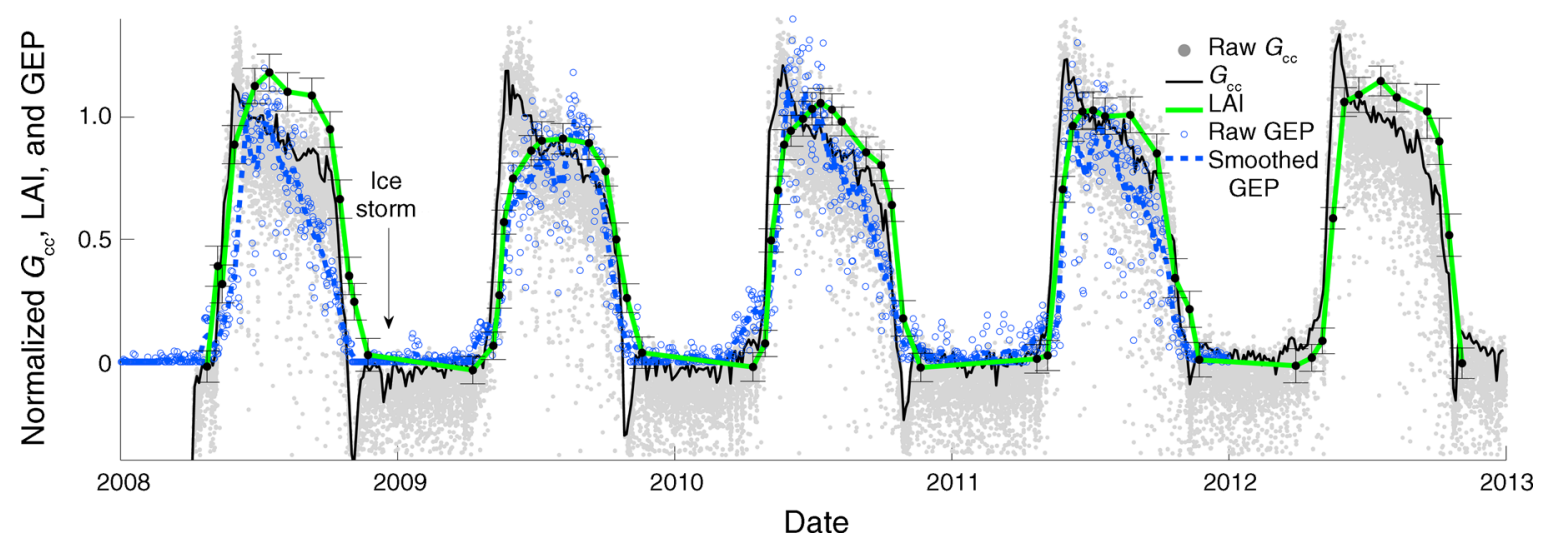

FIG. 1. Observations of leaf area index (LAI; green line), eddy covariance-derived daily gross primary photosynthesis (GEP; dashed blue line), and camera-derived green chromatic coordinate $\left(G_{\mathrm{cc}}\right.$; black line) for five years at Harvard Forest, Massachusetts, USA. All values are normalized relative to the mean annual maximum and minimum values. An ice storm in December of 2008 is indicated, which caused severe structural damage to the forest.
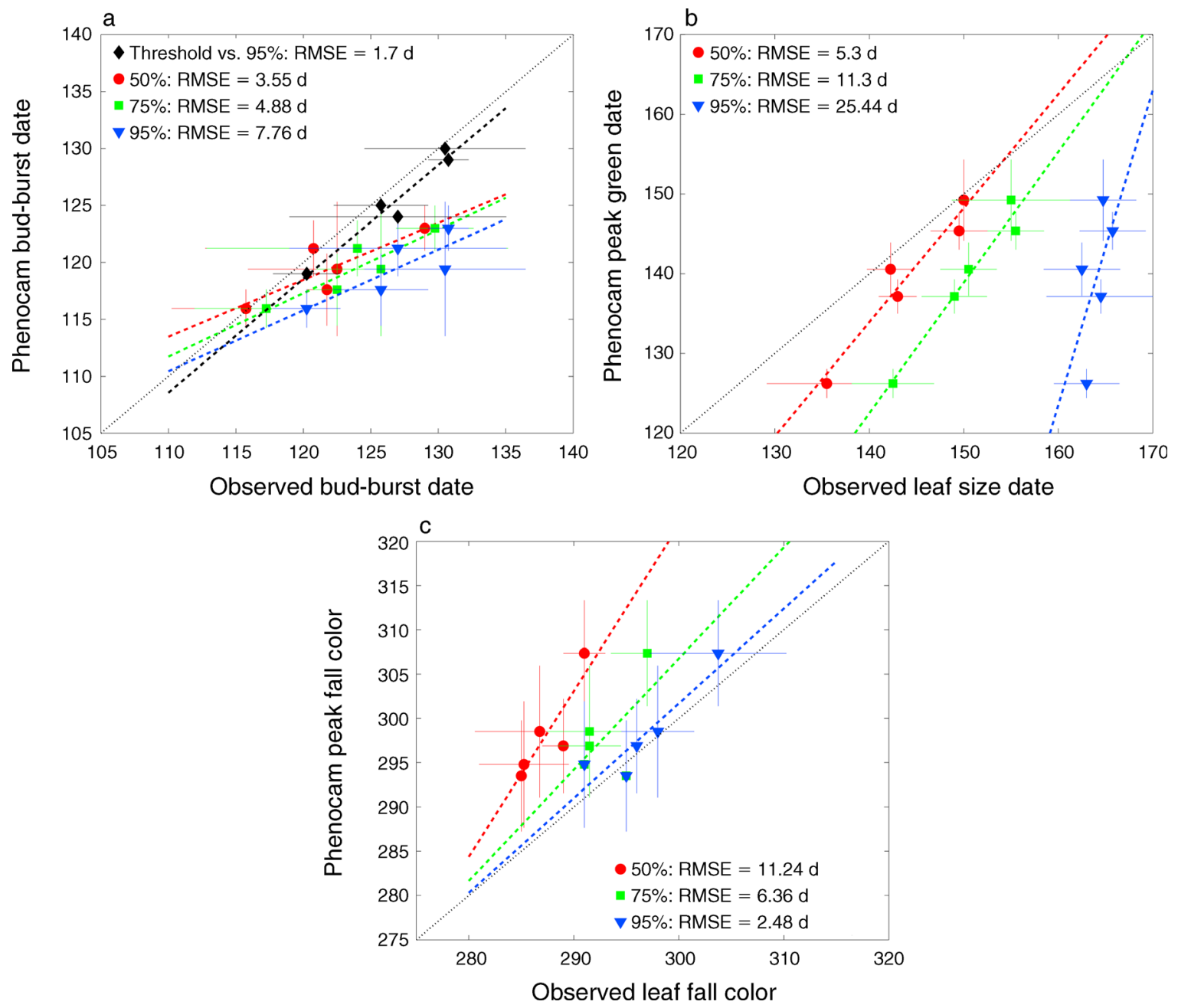

FIG. 2. Camera-derived phenophase transitions (bud burst, peak green, end of fall) compared with ground observations of bud burst, leaf size, and leaf fall color at 50\%,75\%, and $95 \%$ of their maximum annual value. All phenophase transitions are derived using a green-down sigmoid curve fit to the camera $G_{\mathrm{cc}}$ data, with the exception of spring bud burst dates extracted using a simple $G_{\mathrm{cc}}$ threshold of 0.38 , shown in panel (a). RMSE is root mean-square error. Dates are day of the year, with $1 \mathrm{January}=1$. 

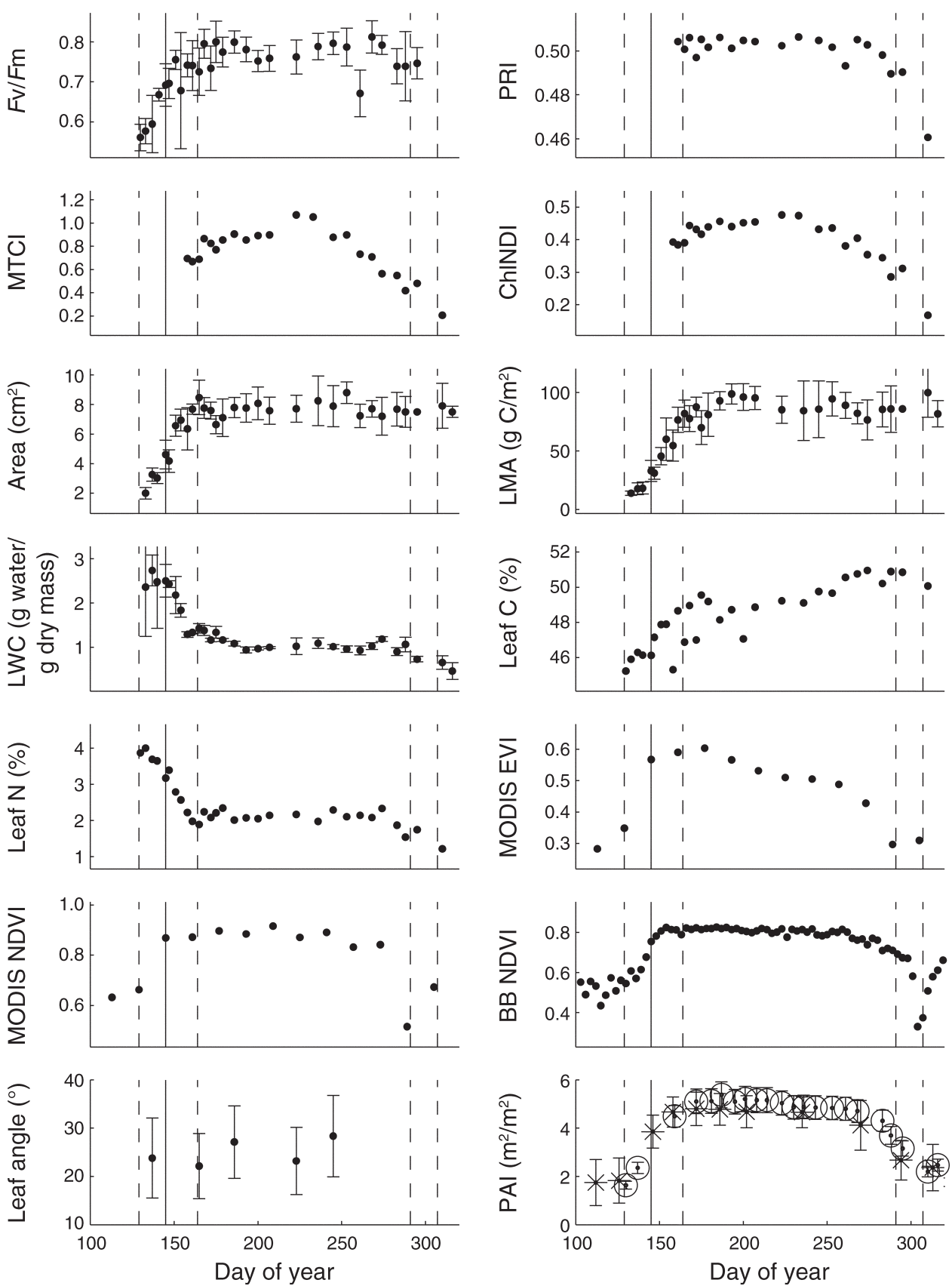

FIG. 3. Measurements of leaf fluorescence (given as the ratio of variable fluorescence to maximum fluorescence $F \mathrm{~V} / \mathrm{Fm}$ ), spectral indices (photochemical reflectance index [PRI], MERIS terrestrial chlorophyll index [MTCI], chlorophyll normalized difference index [ChlNDI]), leaf area, mass per area (LMA), water content (LWC), percentage of carbon (C), percentage of nitrogen $(\mathrm{N})$, moderate resolution imaging spectroradiometer (MODIS) enhanced vegetation index (EVI) and normalized difference vegetation index (NDVI), broadband NDVI (BB NDVI), mean leaf angle, and plant area index (PAI) derived from fPAR (fraction of absorbed photosynthetically active radiation [PAR]; stars) and leaf area index LAI-2000 (circles). Dashed vertical lines represent ground observations of 50\% bud burst, $95 \%$ leaf size, $50 \%$ leaf color, and $50 \%$ leaf fall. Solid vertical lines mark the date of camera-derived peak green. Note that end of autumn near-zero values of $F \mathrm{v} / F \mathrm{~m}$ are not shown.

used the linear mixing model defined by Eq. 1. The model, with one free parameter, accurately reproduced the seasonal cycle of camera $G_{\mathrm{cc}}\left(R^{2}=0.98, P<0.001\right)$, including the dynamics of the spring peak green (Fig. 5). This shows that camera-derived canopy greenness is a combination of leaf color and background color, with the proportional contribution of each being linearly related to gap fraction. Gap fraction is a nonlinear function of leaf area, compounded by the oblique (rather than nadir) view angle of the camera. 
FIG. 4. Red, green, and blue digital numbers extracted from scanned red oak leaves during the growing season of 2011. Reference colors were included in each image (dashed red, green, and blue lines). The extracted digital numbers were used to calculate the green chromatic coordinate for each image (dashed black line). Actual leaf colors for each sample date are given as reference (filled circles).

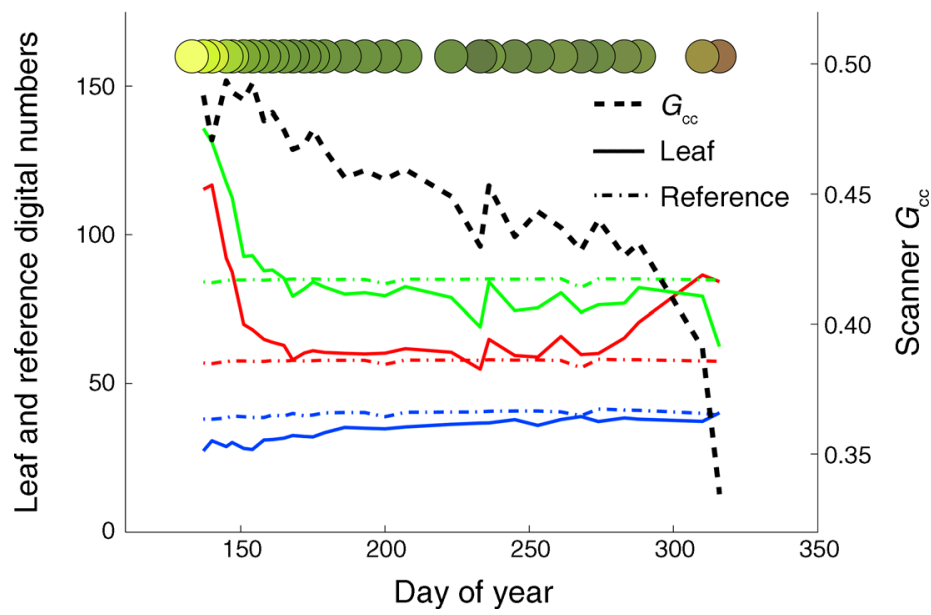

structure, and leaf-level physiological and morphological traits. The results show that camera-derived canopy greenness can effectively identify interannual variability in spring bud burst and autumn senescence. That said, the rate of increase in spring canopy greenness and the date at which peak green is reached was not a linear function of LAI. On average, peak green occurred two weeks before maximum LAI, and spring dynamics in physiological and morphological leaf traits (e.g., maximum leaf area, chlorophyll fluorescence, leaf mass, nitrogen and carbon content) all lagged the timing of spring peak green from the camera.

Previous studies have hypothesized that the welldefined spring peak in canopy greenness observed at Harvard Forest (and other deciduous-dominated forest sites) is related to changes in leaf-level traits (e.g., pigmentation and LMA), changes in canopy structure (i.e., leaf size, shape, orientation), or some combination thereof (e.g., Sonnentag et al. 2012). We show that the spring peak in canopy greenness, as derived from camera $G_{\mathrm{cc}}$, does not correspond to abrupt changes in any single leaf- or canopy-level trait. Rather, our
FIG. 5. Camera $G_{\text {cc }}$ (observed, diamond) and estimated $G_{\mathrm{cc}}$, estimated using a linear mixing model of leaf area, gap fraction, and leaf color (solid circles). The inset shows the contribution of the two end-members: $m 1$, the contribution of background color extinction $\left(m 1=\left(1-F_{t}\right) G_{\mathrm{cc}}^{\mathrm{B}}\right.$, where $G_{\mathrm{cc}}^{\mathrm{B}}$ is the mean background (winter) camera-derived green chromatic coordinate; Eq. 1) and $F_{t}$ is the fraction of the camera field of view that contains green leaves at time $t$; and $m 2$, the combined contribution of leaf area and color $\left(m 2=F_{t} G_{\mathrm{cc}}^{\mathrm{L}}(t)\right.$, where $G_{\mathrm{cc}}^{\mathrm{L}}(t)$ is the scannerderived green chromatic coordinate of individual leaves at time $t$; Eq. 1).

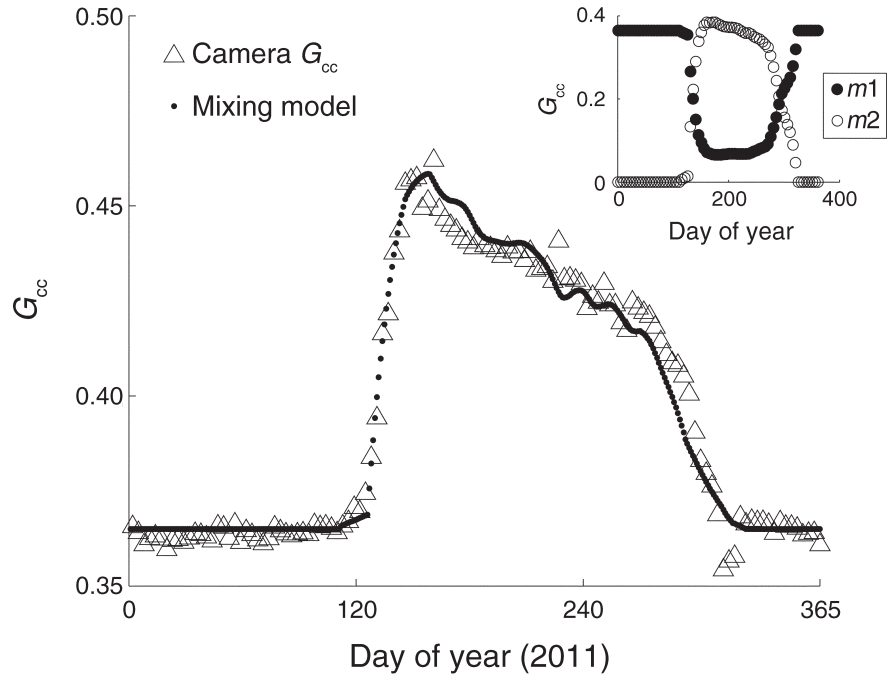


modeling demonstrates that seasonality of canopy greenness, including the timing and shape of the spring peak, is driven by simultaneous changes in both leaf color and canopy structure (i.e., seasonality of leaf area index and gap fraction). The oblique viewing angle of the camera leads to a higher effective LAI within the camera field of view (i.e., the camera sees more layers of leaves than it would if images were taken looking straight down). For spring, this implies a faster increase in canopy greenness than actual increases in LAI. The oblique viewing angle of the camera thus facilitates identification of spring bud burst dates by enhancing the rate of increase in spring $G_{\mathrm{cc}}$. On the other hand, the oblique viewing angle leads to saturation of $G_{\mathrm{cc}}$ at relatively low LAI. During summer, declines in greenness are shown to be linearly related to leaf ontogeny and aging (Jenkins et al. 2007) and related changes in leaf structure and pigmentation, which together influence leaf color. The combined changes demonstrate a strong nonlinear relationship between canopy greenness, canopy structure, and leaf physiology. This also suggests that while it is feasible to back-calculate the seasonality of canopy LAI from a seasonal trajectory of canopy greenness, knowledge of the concurrent changes in the color of individual leaves is needed to do this accurately.

Previous studies (e.g., Hufkens et al. 2012b) indicate that digital camera imagery can be used to detect the impact of disturbances on vegetation. Our results show that $G_{\mathrm{cc}}$ was insensitive to substantial interannual changes in maximum leaf area index, which were primarily caused by damage from a winter ice storm. Other studies have reported similar difficulty in detecting events that induce defoliation (Mizunuma et al. 2013). Our analysis resolves this apparent contradiction in the literature. We show that camera-derived greenness is a saturating, nonlinear function that is driven by developmental changes in leaf color and the affect of leaf area index on the mixing of leaf color with background color showing through gaps in the canopy. Thus, in order for a disturbance to be detectable, it must either cause a change in leaf color or sufficient defoliation to create gaps in the canopy. In our study, for example, $G_{\mathrm{cc}}$ was relatively insensitive to additional increases in leaf area above $\mathrm{LAI} \sim 2.5$.

Based on this result we can identify two classes of disturbance: those that induce leaf color change and canopy gaps (detectable) and those that lower canopy leaf area index but do not create additional gaps within the camera field of view (nondetectable for noncatastrophic levels of leaf loss). For example, the ice storm in the winter of 2008 that led to a $22 \%$ reduction in maximum LAI was not detectable in camera-derived greenness, as no changes in leaf coloration were induced and a reduction in LAI of $22 \%$ was not sufficient to increase the proportion of gaps in the camera field of view. In contrast, the disturbance event examined by Hufkens et al. (2012b) induced leaf coloration before leaf abscission, thus generating a detectable signal in camera-derived greenness. It should be noted, however, that even if leaf coloration is induced, it is possible that a significant proportion of leaves will fall while still green, producing an undetectable change in leaf area index. Further, when damaged leaves fall from the canopy, greenness can increase as previously covered green leaves become visible to the camera. Recent studies have attributed the recovery of greenness postdisturbance to increased leaf area index due to leaf re-flushing (e.g., Hufkens et al. 2012b). Studies using digital repeat photography to characterize the effects of disturbance therefore likely underestimate the true magnitude of the impact of disturbances in closed canopies.

Multiple models exist for extracting phenological information from time series of remotely sensed vegetation indices. Simple thresholds are commonly used (e.g., Richardson et al. 2007), along with curvefitting techniques, such as logistic fits (e.g., Zhang et al. 2003) and more complex sigmoidal models (Elmore et al. 2012), among others (e.g., White et al. 2009). The efficacy of any modeling approach will affect the quality of extracted phenological transition dates, yet few studies have assessed how any given approach affects the results obtained (but see, White et al. [2009], Garrity et al. [2010], Cong et al. [2013]). In our analysis, we show that a fixed-threshold-based approach is more effective for identifying spring bud burst dates than a green-down sigmoid model. While appropriate threshold values depend on camera settings (Sonnentag et al. 2012), the ecosystem or site in question, and may be sensitive to long-term sensor degradation (Ide and Oguma 2010), our results indicate that using a threshold-crossing approach to phenological date estimation can be more accurate than curve-fitting approaches. A detailed comparison of different curve-fitting methods, in combination with simple threshold-based approaches, is needed.

Because autumn phenophase transition dates are much less well-defined than spring counterparts, they have been studied far less. Error estimates of autumn dates extracted from digital images using the greendown sigmoid curve-fit approach were typically three times higher than those extracted for spring as shown by the vertical error bars in Fig. 2. Despite this larger uncertainty, camera-derived autumn dates corresponded closely to ground-based observations of autumn transitions. The more pronounced inflection in MODIS NDVI time series compared to MODIS EVI and MODIS $G_{\mathrm{cc}}$ suggests that the NDVI may be a better indicator of autumn transition points than these other metrics.

Our results show that automated digital cameras can be very effective for detecting the start and end of the growing season, with phenological transition dates derived from canopy imagery corresponding well to direct human observations. However, our results also highlight many factors that affect the interpretation of changes in canopy greenness during the growing season. 

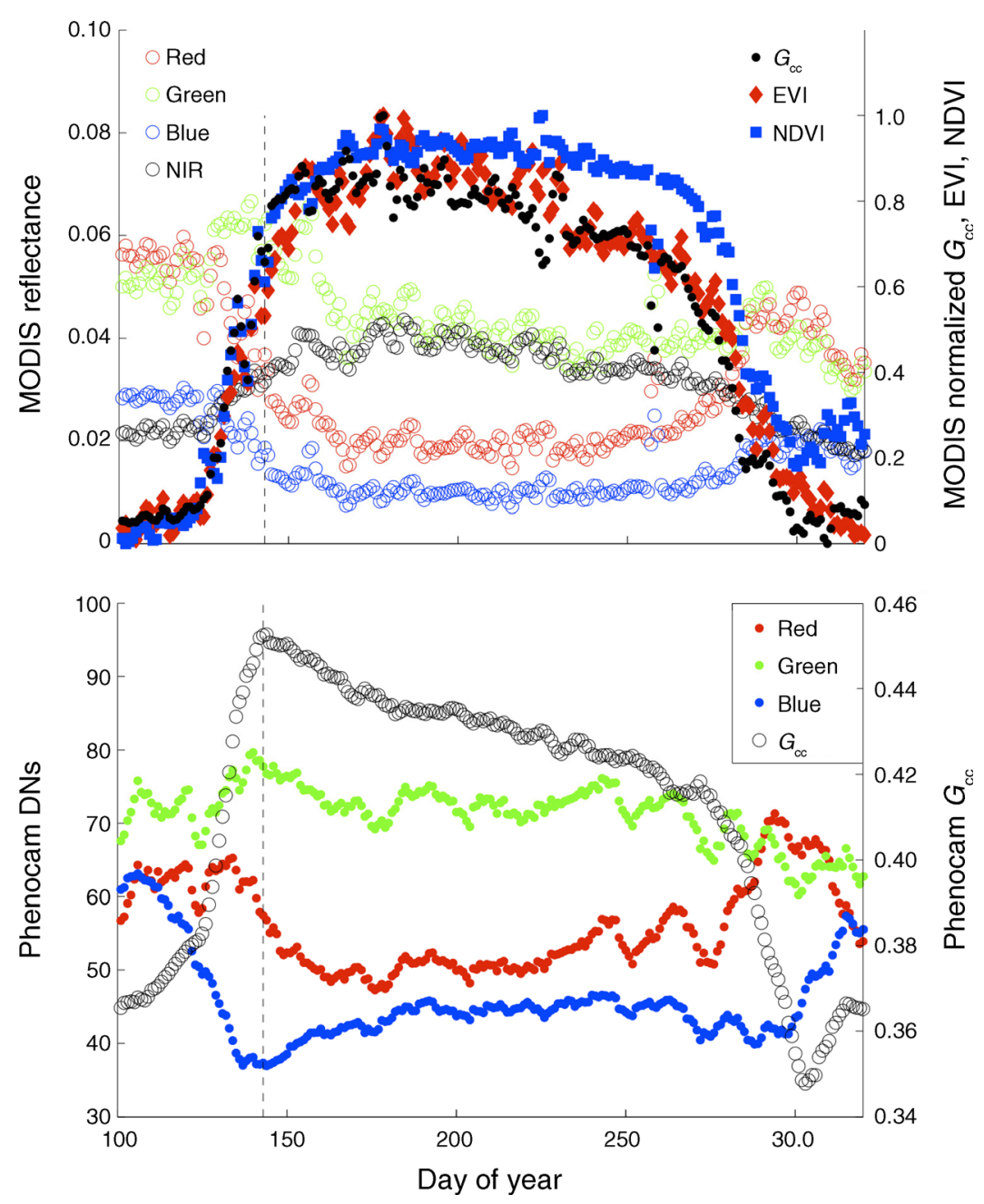

FIG. 6. (a) Mean daily red, green, blue, and near-infrared (NIR) MODIS reflectance for 2001-2011 period, for the pixel centered on the Environmental Measurement Site (EMS) flux tower of the Harvard Forest (Massachusetts, USA), and the derived MODIS $G_{\mathrm{cc}}$, EVI, and NDVI. (b) Mean daily red, green, and blue Phenocam digital numbers (DNs) for the 2008-2012 period at the Harvard Forest and the derived Phenocam $G_{\mathrm{cc}}$. Vertical dashed line indicates the mean peak $G_{\mathrm{cc}}$ over all years.

To maximize the utility of this relatively inexpensive instrument, several developments could be explored to resolve within-growing-season issues. The use of standard, automated digital cameras in combination with high-quality filters provides an opportunity to isolate different parts of the leaf reflectance spectrum. This could enable camera-based vegetation indices to be calculated that are more closely linked to canopy physiology. For instance, near-infrared enabled cameras could provide an opportunity to calculate various broadband (albedo, NDVI) reflectance indices (Steltzer and Welker 2006, Higgins et al. 2011), or a pair of narrowband filters $(530 \pm 5$ and $570 \pm 5 \mathrm{~nm})$ could be used to measure PRI. Combining such cost-effective advances in camera technology with other near-surface remote sensing techniques (e.g., photodiodes [Garrity et al. 2010], light-emitting diodes [Ryu et al. 2010a], spectroradiometers, and commercially available broad- band and narrowband radiometric sensors) have significant potential to advance the field of near-surface remote sensing with automated digital cameras.

\section{CONCLUSION}

The use of automated digital cameras for monitoring vegetation status is becoming widespread. Digital repeat photography has been used to characterize the development of leaf area (Garrity et al. 2011), correlated to canopy $\mathrm{CO}_{2}$ fluxes (e.g., Richardson et al. 2007, 2009, Ahrends et al. 2009, Migliavacca et al. 2011), and compared to satellite-based phenology metrics (Hufkens et al. 2012a). The approach has become central to phenological networks around the world (Richardson et al. 2007, Wingate et al. 2008). Despite the widespread application of automated digital cameras for phenological research, there has yet to be a critical assessment of the relationship between color indices extracted from 
digital repeat photography, leaf physiology, and canopy structure.

We use five years of ground observations of phenology and detailed measurements of canopy structure and leaf physiology, in combination with satellite remote sensing, to show that observed phenological transitions of bud burst and leaf senescence can be well characterized by digital repeat photography. However, the development of canopy leaf area and key physiological and morphological leaf traits lag behind camera-derived green-up in spring. Our mixing model analysis shows that the seasonal cycle of canopy greenness is driven by the combined effects of changes in canopy structure (i.e., seasonality of leaf area index), as well as changes in the color of individual leaves (i.e., ontogeny and associated changes in pigmentation). We discuss implications for the interpretation of seasonal changes in canopy greenness and the use of camera-derived canopy greenness to quantify disturbance impacts. Characterizing the relationship between camera greenness, leaf physiology, and canopy structure across a variety of ecosystems will be a valuable focus of future work.

\section{ACKNOWLEDGMENTS}

B. Darby and E. Felts were supported by Harvard Forest Summer Research Program in Forest Ecology through grants from NSF's Research Experiences for Undergraduates program (award DBI-1003938) and NASA's Global Climate Change Education program. The Richardson Lab acknowledges support from the Northeastern States Research Cooperative, the NSF's Macrosystems Biology program (award EF1065029), the U.S. National Park Service Inventory and Monitoring Program and the USA National Phenology Network (grant number G10AP00129 from the USGS), and the NOAA Climate Program Office, Global Carbon Cycle Program (award NA11OAR4310054). T. F. Keenan acknowledges further support from the Macquarie University Research Fellowship scheme. Research at Harvard Forest is partially supported by the NSF's LTER program (awards DEB0080592, DEB-1237491). The contents of this paper are solely the responsibility of the authors and do not necessarily represent the official views of NSF or USGS.

\section{Literature Cited}

Adams, J. B., D. E. Sabol, V. Kapos, R. A. Filho, D. A Roberts, M. O. Smith, and A. R. Gillespie. 1995. Classification of multispectral images based on fractions of endmembers: application to land-cover change in the Brazilian Amazon. Remote Sensing of Environment 52:137-154.

Ahrends, H. E., R. Brügger, R. Stöckli, J. Schenk, P. Michna, F. Jeanneret, H. Wanner, and W. Eugster. 2008. Quantitative phenological observations of a mixed beech forest in northern Switzerland with digital photography. Journal of Geophysical Research 113:1-11.

Ahrends, H., S. Etzold, W. Kutsch, R. Stoeckli, R. Bruegger, F. Jeanneret, H. Wanner, N. Buchmann, and W. Eugster. 2009. Tree phenology and carbon dioxide fluxes: use of digital photography for process-based interpretation at the ecosystem scale. Climate Research 39:261-274.

Aono, Y., and K. Kazui. 2008. Phenological data series of cherry tree flowering in Kyoto, Japan, and its application to reconstruction of springtime temperatures since the 9th century. International Journal of Climatology 914:905-914.

Barford, C. C., S. C. Wofsy, M. L. Goulden, J. W. Munger, E. H. Pyle, S. P. Urbanski, L. Hutyra, S. R. Saleska, D. Fitzjarrald, and K. Moore. 2001. Factors controlling long- and short-term sequestration of atmospheric $\mathrm{CO}_{2}$ in a mid-latitude forest. Science 294:1688-91.

Barr, A. G., T. A. Black, E. H. Hogg, N. Kljun, K. Morgenstern, and Z. Nesic. 2004. Interannual variability in the leaf area index of a boreal aspen-hazelnut forest in relation to net ecosystem production. Agricultural and Forest Meteorology 126:237-255.

Cong, N., T. Wang, H. Nan, Y. Ma, X. Wang, R. B. Myneni, and S. Piao. 2013. Changes in satellite-derived spring vegetation green-up date and its linkage to climate in China from 1982 to 2010: a multimethod analysis. Global Change Biology 19:881-891.

Dash, J., and P. J. Curran. 2004. The MERIS terrestrial chlorophyll index. International Journal of Remote Sensing 25(23):5403-5413.

Elmore, A. J., S. M. Guinn, B. J. Minsley, and A. D. Richardson. 2012. Landscape controls on the timing of spring, autumn, and growing season length in mid-Atlantic forests. Global Change Biology 18:656-674.

Gamon, J. A., J. Peñuelas, and C. B. Field. 1992. A narrowwaveband spectral index that tracks diurnal changes in photosynthetic efficiency. Remote Sensing of Environment 41:35-44.

Gamon, J., L. Serrano, and J. S. Surfus. 1997. The photochemical reflectance index: an optical indicator of photosynthetic radiation use efficiency across species, functional types, and nutrient levels. Oecologia 112:492-501.

Gamon, J. A., and J. S. Surfus. 1999. Assessing leaf pigment content and activity with a reflectometer. New Phytologist $143: 105-117$

Garrity, S. R., G. Bohrer, K. D. Maurer, K. L. Mueller, C. S. Vogel, and P. S. Curtis. 2011. A comparison of multiple phenology data sources for estimating seasonal transitions in deciduous forest carbon exchange. Agricultural and Forest Meteorology 151:1741-1752.

Garrity, S. R., L. A. Vierling, and K. Bickford. 2010. A simple filtered photodiode instrument for continuous measurement of narrowband NDVI and PRI over vegetated canopies. Agricultural and Forest Meteorology 150:489-496.

Gitelson, A. A., O. B. Chivkunova, and M. N. Merzlyak. 2009. Nondestructive estimation of anthocyanins and chlorophylls in anthocyanic leaves. American Journal of Botany 96:18611868.

Gitelson, A. A., G. P. Keydan, and M. N. Merzlyak. 2006. Three-band model for noninvasive estimation of chlorophyll, carotenoids, and anthocyanin contents in higher plant leaves. Geophysical Research Letters 33:L11402.

Higgins, S. I., M. D. Delgado-Cartay, E. C. February, and H. J. Combrink. 2011. Is there a temporal niche separation in the leaf phenology of savanna trees and grasses? Journal of Biogeography 38:2165-2175.

Huete, A., K. Didan, T. Miura, E. Rodriguez, X. Gao, and L. Ferreira. 2002. Overview of the radiometric and biophysical performance of the MODIS vegetation indices. Remote Sensing of Environment 83:195-213.

Hufkens, K., M. Friedl, O. Sonnentag, B. H. Braswell, T. Milliman, and A. D. Richardson. 2012a. Linking nearsurface and satellite remote sensing measurements of deciduous broadleaf forest phenology. Remote Sensing of Environment 117:307-321.

Hufkens, K., A. D. Richardson, M. A. Friedl, T. F. Keenan, O. Sonnentag, A. Bailey, and J. O'Keefe. 2012b. Ecological impacts of a widespread frost event following early spring leaf-out. Global Change Biology 18:2365-2377.

Ide, R., and H. Oguma. 2010. Use of digital cameras for phenological observations. Ecological Informatics 5:339-347. IPCC 2007. Summary for policymakers. Page 996 in S. Solomon, D. Qin, M. Manning, Z. Chen, and M. Marq, editors. Climate change 2007: the physical science basis. Contribution of Working Group I to the 4th Assessment Report of the Intergovernmental Panel on Climate Change. Cambridge University Press, Cambridge, UK. 
Jenkins, J., A. D. Richardson, B. Braswell, S. Ollinger, D. Hollinger, and M. Smith. 2007. Refining light-use efficiency calculations for a deciduous forest canopy using simultaneous tower-based carbon flux and radiometric measurements. Agricultural and Forest Meteorology 143:64-79.

Keenan, T. F., E. Davidson, A. M. Moffat, W. Munger, and A. D. Richardson. 2012. Using model-data fusion to interpret past trends, and quantify uncertainties in future projections, of terrestrial ecosystem carbon cycling. Global Change Biology 18:2555-2569.

Lieth, H. 1974. Phenology and seasonality modeling. SpringerBerlin, Berlin, Germany.

Ma, S., D. D. Baldocchi, S. Mambelli, and T. E. Dawson. 2011. Are temporal variations of leaf traits responsible for seasonal and interannual variability in ecosystem $\mathrm{CO}_{2}$ exchange? Functional Ecology 25:258-270.

McKown, A. D., R. D. Guy, M. S. Azam, E. C. Drewes, and L. K. Quamme. 2013. Seasonality and phenology alter functional leaf traits. Oecologia 172:653-665.

Migliavacca, M., et al. 2011. Using digital repeat photography and eddy covariance data to model grassland phenology and photosynthetic $\mathrm{CO}_{2}$ uptake. Agricultural and Forest Meteorology 151:1325-1337.

Migliavacca, M., O. Sonnentag, T. F. Keenan, A. Cescatti, J. O'Keefe, and A. D. Richardson. 2012. On the uncertainty of phenological responses to climate change, and implications for a terrestrial biosphere model. Biogeosciences 9:20632083.

Mizunuma, T., M. Wilkinson, E. L. Eaton, M. Mencuccini, J. I. L. Morison, and J. Grace. 2013. The relationship between carbon dioxide uptake and canopy colour from two camera systems in a deciduous forest in southern England. Functional Ecology 27:196-207.

Peñuelas, J., T. Rutishauser, and I. Filella. 2009. Phenology feedbacks on climate change. Science 324:887-888.

Pisek, J., Y. Ryu, and K. Alikas. 2011. Estimating leaf inclination and G-function from leveled digital camera photography in broadleaf canopies. Trees 25:919-924.

Pisek, J., O. Sonnentag, A. D. Richardson, and M. Mõttus. 2013. Is the spherical leaf inclination angle distribution a valid assumption for temperate and boreal broadleaf tree species? Agricultural and Forest Meteorology 169:186-194.

Richardson, A. D., and G. P. Berlyn. 2002. Changes in foliar spectral reflectance and chlorophyll fluorescence of four temperate species following branch cutting. Tree Physiology 22:499-506.

Richardson, A. D., B. H. Braswell, D. Y. Hollinger, J. P. Jenkins, and S. V. Ollinger. 2009. Near-surface remote sensing of spatial and temporal variation in canopy phenology. Ecological Applications 19:1417-1428.

Richardson, A. D., J. P. Jenkins, B. H. Braswell, D. Y. Hollinger, S. V. Ollinger, and M.-L. Smith. 2007. Use of digital webcam images to track spring green-up in a deciduous broadleaf forest. Oecologia 152:323-334.

Richardson, A. D., T. F. Keenan, M. Migliavacca, Y. Ryu, O. Sonnentag, and M. Toomey. 2013a. Climate change, phenology, and phenological control of vegetation feedbacks to the climate system. Agricultural and Forest Meteorology 169:156-173.

Richardson, A. D., S. Klosterman, and M. Toomey. $2013 b$. Near-surface sensor-derived phenology. Pages 413-430 in M. D. Schwartz, editor. Phenology: an integrative environmental science. Springer, New York, USA.
Richardson, A. D., and J. O'Keefe. 2009. Phenological differences between understory and overstory: a case study using the long-term Harvard forest records. Pages 87-117 in A. Noormets, editor. Phenology of ecosystem processes. Springer New York, New York, USA.

Ryu, Y., D. D. Baldocchi, J. Verfaillie, S. Ma, M. Falk, I. RuizMercado, T. Hehn, and O. Sonnentag. 2010a. Testing the performance of a novel spectral reflectance sensor, built with light emitting diodes (LEDs), to monitor ecosystem metabolism, structure and function. Agricultural and Forest Meteorology 150:1597-1606.

Ryu, Y., T. Nilson, H. Kobayashi, O. Sonnentag, B. E. Law, and D. D. Baldocchi. 2010b. On the correct estimation of effective leaf area index: Does it reveal information on clumping effects? Agricultural and Forest Meteorology 150:463-472.

Ryu, Y., O. Sonnentag, T. Nilson, R. Vargas, H. Kobayashi, R. Wenk, and D. D. Baldocchi. 2010c. How to quantify tree leaf area index in an open savanna ecosystem: A multi-instrument and multi-model approach. Agricultural and Forest Meteorology 150:63-76.

Smolander, H., and P. Stenberg. 1996. Response of LAI-2000 estimates to changes in plant surface area index in a Scots pine stand. Tree physiology 16:345-349.

Sonnentag, O., K. Hufkens, C. Teshera-Sterne, A. M. Young, M. Friedl, B. H. Braswell, T. Milliman, J. O'Keefe, and A. D. Richardson. 2012. Digital repeat photography for phenological research in forest ecosystems. Agricultural and Forest Meteorology 152:159-177.

Steltzer, H., and J. M. Welker. 2006. Modeling the effect of photosynthetic vegetation properties on the NDVI-LAI relationship. Ecology 87:2765-2772.

Thompson, R., and R. M. Clark. 2008. Is spring starting earlier? Holocene 18:95-104.

Urbanski, S., C. Barford, S. Wofsy, C. Kucharik, E. Pyle, J. Budney, K. McKain, D. Fitzjarrald, M. Czikowsky, and J. W. Munger. 2007. Factors controlling $\mathrm{CO}_{2}$ exchange on timescales from hourly to decadal at Harvard Forest. Journal of Geophysical Research 112:1-25.

Vermote, E., S. Kotchenova, and J. Ray. 2011. MODIS surface reflectance user's guide. Version 1.3. http://modis-sr.ltdri.org/ products/MOD09_UserGuide_v1_3.pdf

White, M. A., et al. 2009. Intercomparison, interpretation, and assessment of spring phenology in North America estimated from remote sensing for 1982-2006. Global Change Biology 15:2335-2359.

Wingate, L., A. D. Richardson, J. F. Weltzin, K. N. Nasahara, and J. Grace. 2008. Keeping an eye on the carbon balance: linking canopy development and net ecosystem exchange using a webcam network. FluxLetter 1:14-17.

$\mathrm{Xu}$, L., et al. 2013. Temperature and vegetation seasonality diminishment over northern lands. Nature Climate Change 3:581-586.

Zhang, X., M. A. Friedl, and C. B. Schaaf. 2006. Global vegetation phenology from moderate resolution imaging spectroradiometer (MODIS): evaluation of global patterns and comparison with in situ measurements. Journal of Geophysical Research 111:1-14.

Zhang, X., M. A. Friedl, C. B. Schaaf, A. H. Strahler, J. C. F. Hodges, F. Gao, B. C. Reed, and A. Huete. 2003. Monitoring vegetation phenology using MODIS. Remote Sensing of Environment 84:471-475.

\section{Supplemental Material}

\section{Appendix}

A comparison of seasonal changes in the green chromatic coordinate $\left(G_{\mathrm{cc}}\right)$ vs. seasonal changes in hue (Ecological Archives A024-086-A1). 